University of Wollongong

Research Online

Australian Institute for Innovative Materials -

Papers

Australian Institute for Innovative Materials

2013

Flexible cellulose based polypyrrole-multiwalled carbon nanotube films for bio-compatible zinc batteries activated by simulated body fluids

Sha Li

University of Wollongong, sl739@uowmail.edu.au

Zai Ping Guo

University of Wollongong, zguo@uow.edu.au

Cai Yun Wang

University of Wollongong, caiyun@uow.edu.au

Gordon G. Wallace

University of Wollongong, gwallace@uow.edu.au

Hua-Kun Liu

University of Wollongong, hua@uow.edu.au

Follow this and additional works at: https://ro.uow.edu.au/aiimpapers

Part of the Engineering Commons, and the Physical Sciences and Mathematics Commons

Research Online is the open access institutional repository for the University of Wollongong. For further information contact the UOW Library: research-pubs@uow.edu.au 


\title{
Flexible cellulose based polypyrrole-multiwalled carbon nanotube films for bio- compatible zinc batteries activated by simulated body fluids
}

\author{
Abstract \\ This work aims to develop biocompatible non-toxic materials for implantable bio-electronic cells. \\ Polypyrrole (PPy)-carbon nanotube (CNT) composites with varied ratios of PPy to CNTs were chemically \\ synthesized and used as cathodes with the support of cellulose paper. Zinc foil was used as the anode \\ material due to its non-toxicity and moderate dissolution rate in aqueous solutions. Simulated body fluids \\ (SBFs) with various protein concentrations were applied as electrolytes in this battery system. The \\ $\mathrm{PPy}-\mathrm{CNT} \mid \mathrm{Zn}$ cell is capable of being discharged up to 24.5 hours at a current density of $60 \mu \mathrm{A} \mathrm{cm}{ }^{-2}$ in a \\ protein free SBF. The batteries have also been tested in vitro using SBFs containing bovine serum albumin \\ (BSA) with different concentrations. Such a battery can be charged up to 35.1 hours (1.26 W h) in the \\ electrolyte containing $8 \mathrm{~g} \mathrm{~L}^{-1} \mathrm{BSA}$, which is $10 \%$ of the genuine protein concentration of blood plasma. \\ The effects of adding BSA to the electrolyte on both the anodic reactions and the redox capabilities of the \\ PPy-CNT cathodes are also investigated.

\section{Keywords} \\ compatible, bio, films, nanotube, carbon, multiwalled, zinc, polypyrrole, fluids, cellulose, flexible, batteries, \\ activated, body, simulated \\ Disciplines \\ Engineering | Physical Sciences and Mathematics

\section{Publication Details} \\ Li, S., Guo, Z., Wang, C., Wallace, G. G. \& Liu, H. (2013). Flexible cellulose based polypyrrole-multiwalled \\ carbon nanotube films for bio-compatible zinc batteries activated by simulated body fluids. Journal of \\ Materials Chemistry A, 1 (45), 14300-14305.
}




\title{
Flexible cellulose based polypyrrole - multiwalled carbon nanotube films for bio-compatible zinc battery activated by simulated body fluid
}

\author{
Sha Li ${ }^{\text {a, b }}$, Zai Ping Guo ${ }^{\mathrm{a}}$, Cai Yun Wang ${ }^{\mathrm{b}}$, Gordon G. Wallace ${ }^{\mathrm{b}}$, Hua Kun Liu ${ }^{\mathrm{a}, \mathrm{b}}$ * \\ Received (in $X X X, X X X) X$ th $X X X X X X X X X 20 X X$, Accepted $X$ th $X X X X X X X X X 20 X X$ \\ 5 DOI: 10.1039/b000000x
}

This work aims to develop biocompatible non-toxic materials for implantable bio-electronic cells.

Polypyrrole (PPy)/carbon nanotube (CNT) composites with varied ratios of PPy to CNT were chemically synthesized and used as cathode with the support of cellulose paper. Zinc foil was used as the anode material due to its non-toxicity and moderate dissolution rate in aqueous solutions. Simulated body fluid

10 (SBF) with various protein concentrations was applied as the electrolyte in this battery system. The $\mathrm{PPy} / \mathrm{CNT} \mid \mathrm{Zn}$ cell is capable of being discharged up to 24.5 hours at a current density of $60 \mu \mathrm{A} \mathrm{cm}$ in protein free SBF. The batteries have also been tested in vitro using SBF containing bovine serum albumin (BSA) with different concentrations. Such a battery can be charged up to 35.1 hours (1.26 $\mathrm{mWh}$ ) in the electrolyte containing $8 \mathrm{~g} \mathrm{~L}^{-1} \mathrm{BSA}$, which is $10 \%$ of the genuine protein concentration of blood plasma.

15 The effects of adding BSA to the electrolyte on both the anodic reaction and the redox capabilities of the $\mathrm{PPy} / \mathrm{CNT}$ cathodes are also investigated.

\section{Introduction}

In recent years, progress in the development of biomedical microdevices has spontaneously stimulated interest in designing micro-

20 batteries as power sources ${ }^{1,2}$. Research attempts to fabricate biocompatible batteries with reliable power outputs have had some preliminary success. Some ingenious battery designs are quite promising for clinical applications targeted at implantable medical micro-devices such as endoscopes ${ }^{3}$, telemetric devices ${ }^{4}$,

25 hearing aid devices ${ }^{5,}{ }^{6}$, self-diagnosis devices $^{7}$ and cardiac pacemakers $^{8,9}$. Meanwhile, research work aimed at utilizing the different types of biofluids as electrolyte has been carried out internationally, for instance, batteries activated by urine ${ }^{10}$ and gastric fluids ${ }^{3}$ to generate electric power for medical micro-

30 devices. Such batteries usually are capable of being operated under low current density with long and stable discharge life.

Generally, a battery which is eligible to be defined as a "biobattery" has to be either biocompatible for in-vivo usage or able to convert energy from natural sources. There are several

35 principles that are crucial for achieving in-vivo implantation. First, the materials for constructing the battery have to be biocompatible with no generation of toxic emissions during electrochemical processes. Second, the battery needs to function as a reliable power source with a long service life. Third, the

40 battery should be small, and furthermore, better to be soft and flexible $^{11,12}$. Among all these research directions for developing a "bio-batteries", ultra-flexible, thin-film-based, implantable batteries are one of the most popular and promising objectives. They are under development in laboratories worldwide for

45 various clinical application purposes. A representative device is a nanocomposite paper battery developed by Pushparaj et $a l^{13}$. In their work, the cathode, the anode, and the separator were made into an integrated unit with excellent flexibility. This work greatly inspired us to make paper-based batteries that are capable 50 of functioning as dry body implants, which can be activated by the body fluids in vivo.

In this work, we have developed a simple and economical method for making flexible electrodes by coating polypyrrole (PPy)/multiwalled carbon nanotube (CNT) composite on

55 cellulose membranes. Lightweight PPy was coated on miniscule multiwalled CNTs (MWCNTs) via the chemical polymerization method, yielding a nanostructured composite with high porosity and large surface area. The full battery was constructed using the deposited PPy/CNT thin layer as the cathode. Previous work has

60 proved that the biocompatibility of immobilized multiwalledCNT-based implants is comparable with that of the existing medical grade materials ${ }^{14}$. Zinc was chosen as the anode material, mainly due to its moderate interface reactions in aqueous electrolyte. In addition, $\mathrm{Zn}$ is considered to be biocompatible. The

65 amount of zinc commonly consumed in self-selected supplements for adult is $15-100 \mathrm{mg}$ daily $^{15,16}$. The battery uses simulated body fluids as electrolyte and exhibits a long discharge plateau under a discharge rate of $60 \mu \mathrm{A} \mathrm{cm} \mathrm{cm}^{-2}$, indicating that the battery could be a promising power source for most implantable medical micro70 devices.

\section{Experimental}

\subsection{Preparation of the CNT-PPy composite thin layer}

The MWCNTs were treated with a refluxing acid mixture of $65 \%$ $\mathrm{HNO}_{3}$ and $98 \% \mathrm{H}_{2} \mathrm{SO}_{4}\left(\mathrm{v}\left(\mathrm{HNO}_{3}\right): \mathrm{v}\left(\mathrm{H}_{2} \mathrm{SO}_{4}\right)=3: 1\right)$ for 12 hours. 75 The carboxylic acid group functionalized MWCNTs were then 
centrifuged and rinsed with deionised water to remove the acid residues until its $\mathrm{pH}$ reached 6.5. The obtained functionalized MWCNT powder was dried at $60{ }^{\circ} \mathrm{C}$ in a vacuum oven for 12 hours. $40 \mathrm{mg}$ of the as-prepared powder was uniformly dispersed

5 in $100 \mathrm{ml}$ deionised water by ultrasonication using $500 \mathrm{mg}$ sodium 4-dodecylbenzenesulfonic acid (SDBS) as the surfactant. The PPy/CNT composites were prepared by chemical polymerization. Three types of composites were prepared, keeping the amount of CNT constant, but varying the pyrrole

10 monomer concentration as: $0.2,0.1$, and $0.05 \mathrm{M}$. $100 \mathrm{ml} 0.25 \mathrm{M}$ iron trichloride solution was added dropwise into the pyrroleCNT suspension placed in an ice bath. The resulting mixture was left overnight to achieve full oxidation, followed by filtration, thorough rinsing, and vacuum drying.

\subsection{Battery construction}

$0.4 \mathrm{mg} \mathrm{ml}^{-1} \mathrm{PPy} / \mathrm{CNT}$ aqueous suspension was prepared by ultrasonication. Thin layers of PPy/CNT were deposited on cellulose filter membranes by filtrating $10 \mathrm{ml}$ of the suspension. The PPy/CNT thin layer was applied as the cathode material, 20 with the cellulose membrane as the substrate and separator. Fig. 1 shows the flexibility of the cellulose based PPy/CNT electrodes.
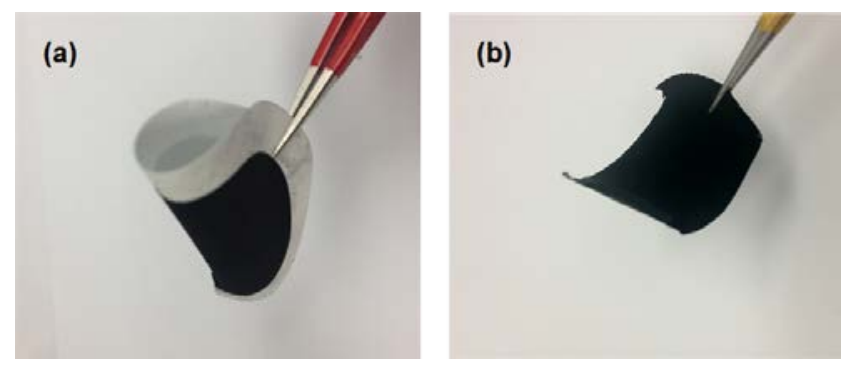

Fig.1 Digital picture of (a) a folded cellulose based PPy/CNT electrode and (b) peeled off PPy/CNT film

Zinc foil was cut to a size of $1 \times 1 \mathrm{~cm}$, polished, and washed

25 with acetone prior to use. Both the zinc anode and the PPy/CNT cathode were immersed in a beaker filled with electrolyte to a fixed height of $1 \mathrm{~cm}$. The electrolyte was the modified simulated body fluid with content of $0,8,16$, and $40 \mathrm{~g} \mathrm{~L}^{-1}$ bovine serum albumin (BSA). This electrolyte has the same ionic composition

30 as human blood plasma, but without glucose or protein. The concentrations of BSA in the three types of electrolyte were $10 \%$, $20 \%$, and $40 \%$ of the BSA protein in genuine body fluid, which is reported as $80 \mathrm{~g} \mathrm{~L}^{-117}$. A full battery sealed by water permeable paper has also been made and tested using the SBF electrolyte

35 containing $8 \mathrm{~g} \mathrm{~L}^{-1} \mathrm{BSA}$.

\subsection{Characterization}

3. The surface morphology of the PPy/CNT powder was observed with a field emission scanning electron microscope 40 (FESEM, JOEL 7500) and a transmission electron microscope (TEM, Philips CM12) with an accelerating voltage of $120 \mathrm{kV}$. The Raman measurements were performed with a JOBIN YVON HR800 Confocal Raman system with $632.8 \mathrm{~nm}$ diode laser excitation on a 300 lines $/ \mathrm{mm}$ grating at room temperature.

45 Electrochemical impedance spectroscopy (EIS) measurements and cyclic voltammetry (CV) were carried out on a $\mathrm{CH}$ workstation (CHI 660B). The battery discharge tests were carried out by using a battery testing device (Landlt Co., China). The cells were discharged from the open circuit potential to $0.6 \mathrm{~V}$

50 under a discharge current density of $60 \mu \mathrm{A} \mathrm{cm} \mathrm{cm}^{-2}$. Polarization curves of $\mathrm{Zn}$ foil in different electrolytes were also obtained with the $\mathrm{CH}$ workstation (CHI 660B). Specific areas of samples were tested with a Nova 1000 Brunauer-Emmett-Teller (BET) surface area analyzer, and the sample conductivities were tested with a 55 JANDEL RM3 four point probe instrument.

\section{Results and discussion}

\subsection{Characterization of as-prepared PPy/CNT composites}

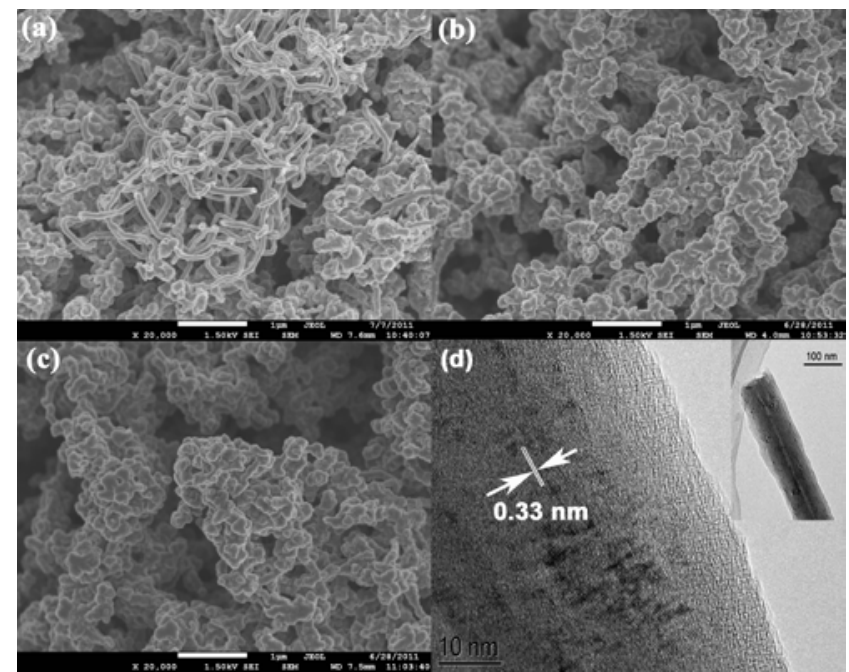

Fig.2 FESEM images of PPy/CNT composites prepared from (a)

$600.05 \mathrm{M}$ pyrrole $+0.4 \mathrm{mg} \mathrm{ml}^{-1} \mathrm{CNT}$, (b) $0.1 \mathrm{M}$ pyrrole $+0.4 \mathrm{mg}$ $\mathrm{ml}^{-1} \mathrm{CNT}$, and (c) $0.2 \mathrm{M}$ pyrrole $+0.4 \mathrm{mg} \mathrm{ml}^{-1} \mathrm{CNT}$; and (d) high resolution TEM image of composite made from $0.1 \mathrm{M}$ pyrrole + $0.4 \mathrm{mg} \mathrm{ml}^{-1} \mathrm{CNT}$.

65 Fig. 2(a-c) presents FESEM images of PPy/CNT composites synthesized with different monomer concentrations. The composites generally have a porous structure formed from the entangled PPy-coated CNTs or CNT network. As the monomer concentration increases, however, the agglomeration of $\mathrm{PPy}$

70 particles becomes more noticeable, and this decreases the specific surface area, as shown in Fig. 2(c). According to the BET and conductivity testing results, the specific surface areas of these composites prepared from $0.2 \mathrm{M}$ pyrrole, $0.1 \mathrm{M}$ pyrrole, and 0.05 $\mathrm{M}$ pyrrole were $16.07 \mathrm{~m}^{2} \mathrm{~g}^{-1}, 20.14 \mathrm{~m}^{2} \mathrm{~g}^{-1}$, and $24.65 \mathrm{~m}^{2} \mathrm{~g}^{-1}$, 75 respectively. They exhibited conductivity of $94 \mathrm{~S} \mathrm{~cm}^{-1}(0.05 \mathrm{M}$ pyrrole $\left.+0.4 \mathrm{mg} \mathrm{ml}^{-1} \mathrm{CNT}\right), 72 \mathrm{~S} \mathrm{~m}^{-1}\left(0.1 \mathrm{M}^{2}\right.$ pyrrole $+0.4 \mathrm{mg}$

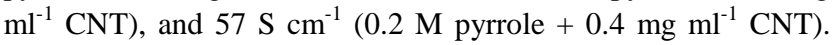
This indicates that an excess amount of pyrrole monomers were polymerized on the PPy-CNT surface induces the stacking of PPy 80 particles and reduces the specific surface area of the composite. The composite synthesized with $0.1 \mathrm{M}$ pyrrole displays a relatively uniform porous structure, as shown in Fig. 2(b). Its TEM image in Fig. 2(d) clearly demonstrates that the hollow MWCNT structure was encapsulated by PPy, which was 85 uniformly polymerized on the surface of the CNT. The lattice spacing of MWCNTS is about $0.34 \mathrm{~nm}$ and the lattices are 
dislocated at the interface which suggests strong bonding between the MWCNT lattice and polypyrrole coating layer.

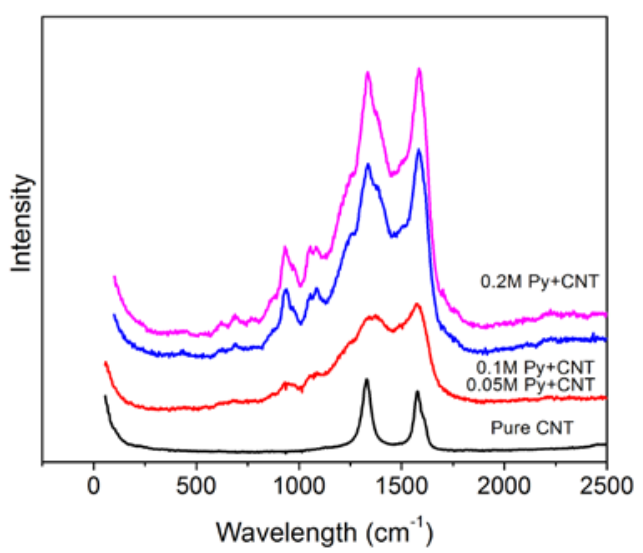

5 Fig.3 Raman spectra of (a) pure MWCNT and composites prepared from (b) $0.05 \mathrm{M}$ pyrrole $+0.4 \mathrm{mg} \mathrm{ml}^{-1} \mathrm{CNT}$, (c) $0.1 \mathrm{M}$

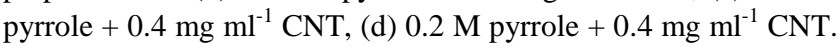

To study the molecular structure of the resulting PPy/CNT

10 composites, Raman spectroscopy was carried out to provide sufficient evidence. Fig. 3 presents the Raman spectra of pure functionalized carbon nanotubes and of composites prepared with different PPy content. All three types of PPy/CNT composite display identical doped PPy structures. The peaks at 1050 and

$15968 \mathrm{~cm}^{-1}$ are associated with the quinonoid polaron structure, and those at 1086 and $940 \mathrm{~cm}^{-1}$ are associated with the quinonoid bipolaron structure ${ }^{18}$. The peak at $1244 \mathrm{~cm}^{-1}$ is considered to be due to the $\mathrm{N}-\mathrm{H}$ in-plane deformation. The pure carbon nanotubes have two very strong peaks at 1355 and $1580 \mathrm{~cm}^{-1}$,

20 which can be respectively associated with the D mode and G mode of carbon bonding vibrations ${ }^{19,20}$. The ranges of these two strong peaks overlap with the ring stretching peak of PPy at 1314 $\mathrm{cm}^{-1}$ and its $\mathrm{C}=\mathrm{C}$ backbone stretching peak at $1610 \mathrm{~cm}^{-1}$. Those peaks associated with bonds of PPy indicate that the PPy has

25 been successfully polymerized on top of the tubular shells of the carbon nanotubes. There is an obvious trend, however, that a composite with less PPy content displays sharper D band and G band stretching peaks which overlap the ring stretching and $\mathrm{C}=\mathrm{C}$ 30 backbone stretching peaks.

\subsection{Battery testing with different PPy/CNT electrodes}

The batteries used zinc foil as the anode material and protein free simulated body fluid (SBF) as the electrolyte. They were assembled with cathodes made from all three types of PPy/CNT

35 composites. The mechanism of such a battery has been considered to be similar to that of a primary metal air battery, according to the previous studies on magnesium/conductive polymer batteries with aqueous electrolyte ${ }^{21,22}$. In this battery system, zinc is the unlimited sacrificial electrode, while PPy/CNT

40 acts as the catalyst for the oxygen reduction process. Fig. 4 displays the discharge curves of the three batteries under the current density of $60 \mu \mathrm{A} \mathrm{cm}{ }^{-2}$. The battery with the electrode prepared from $0.1 \mathrm{M}$ pyrrole $+0.4 \mathrm{mg} \mathrm{ml}^{-1} \mathrm{CNT}$ clearly shows the best discharge performance, with a higher discharge plateau
45 voltage, which is almost $0.1 \mathrm{~V}$ higher than those of the other two types, and its discharge potential drops much more slowly. The differences in discharge performances can be mainly ascribed to the catalyst efficiency of the cathode materials for oxygen reduction. Such efficiency is decided by several properties of the

50 cathode materials, including their specific surface areas, conductivity, and redox capabilities.

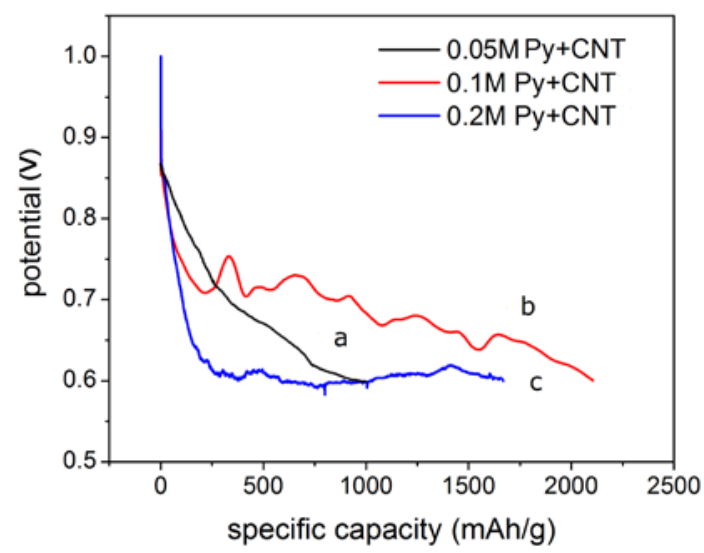

Fig.4 Discharge curves of batteries with different cathodes: (a) $550.05 \mathrm{M}$ pyrrole $+0.4 \mathrm{mg} \mathrm{ml}^{-1} \mathrm{CNT}$, (b) $0.1 \mathrm{M}$ pyrrole $+0.4 \mathrm{mg}$ $\mathrm{ml}^{-1} \mathrm{CNT}$, (c) $0.2 \mathrm{M}$ pyrrole $+0.4 \mathrm{mg} \mathrm{ml}^{-1} \mathrm{CNT}$ in SBF electrolyte (current density $=40 \mathrm{~mA} \mathrm{~g}^{-1}$ ).

The FESEM images (Fig. 2) have provided evidence that the 60 agglomeration of PPy becomes more significant as the PPy content increases in the composite. This induces a decrease in the surface area, where the electron transportation and redox reaction occur. Meanwhile, excess PPy coated on CNT reduces the conductivity offered by the carbon nanotubes. Thus, the

65 discharge plateau of the battery with its cathode made from $0.2 \mathrm{M}$ pyrrole + CNT displays a lower plateau voltage due to its relatively lower specific surface area and lower conductivity. On the other hand, polypyrrole works as an oxygen reduction catalyst, which helps to retain the discharge plateau.

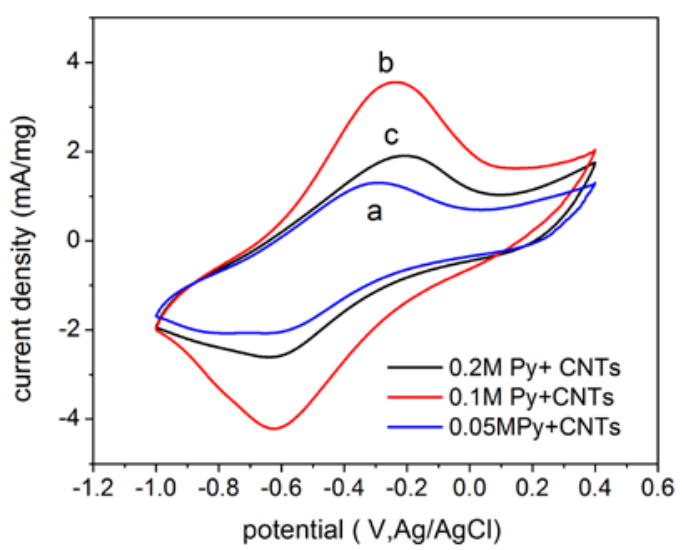

Fig.5 Cyclic voltammetry of different electrodes in SBF electrolyte: (a) $0.05 \mathrm{M}$ pyrrole $+0.4 \mathrm{mg} \mathrm{ml}^{-1} \mathrm{CNT}$, (b) $0.1 \mathrm{M}$

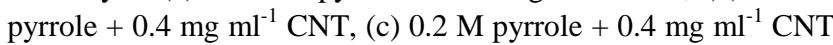
(scan rate $=10 \mathrm{mV} \mathrm{s}^{-1}$ ).

75 Fig. 5 shows cyclic voltammetry (CV curves) at the same scan 
rate $\left(10 \mathrm{mV} \mathrm{S}^{-1}\right)$ of all three cathodes made from the different composites. The maximum potential of the redox peaks suggests that the redox capabilities of the composites made from $0.05 \mathrm{M}$ ppy + CNT are significantly lower than the other two types of 5 cathode materials. This could explain the absence of a discharge plateau in the battery with the cathode made from $0.05 \mathrm{M}$ pyrrole $+\mathrm{CNT}$, in which case, the oxygen reduction is quickly inactivated when the PPy/CNT composite completely loses its redox activity. To verify this, electrochemical impedance spectra 10 of all three types of batteries were collected after 6 hours discharge (when the batteries with cathode made from $0.1 \mathrm{M}$ pyrrole + CNT and $0.2 \mathrm{M}$ pyrrole + CNT reach their discharge plateaus) and are shown in Fig. 6.

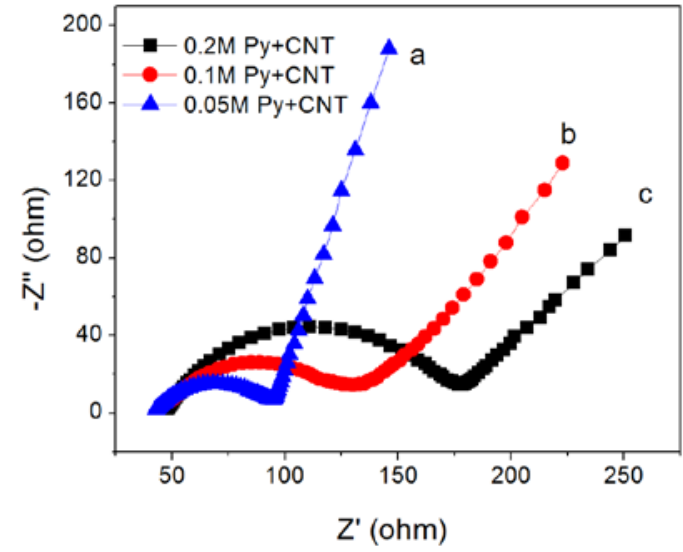

15

Fig.6 Electrochemical impedance spectroscopy of batteries with electrodes made from (a) $0.05 \mathrm{M}$ pyrrole $+0.4 \mathrm{mg} \mathrm{ml}^{-1} \mathrm{CNT}$, (b) 60

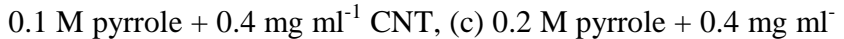
${ }^{1} \mathrm{CNT}$ after 6 hours discharge.

20

The first semicircles displayed in the curves usually correspond to the interface charge transfer resistance, together with the contact resistance between the electrodes and the current collector $^{23,24}$. The charge transfer resistance, $R_{c t}$, of the electrode

25 made from $0.05 \mathrm{M}$ pyrrole $+\mathrm{CNT}$ is calculated as $126 \Omega$, which is significantly larger than for the other two types of batteries. The large internal resistance can be mainly ascribed to the inactive cathode material, which loses its function as the oxygen reduction catalyst after a few hours of discharge, which 30 consequently induces a constant drop in the discharge potential.

\subsection{Testing of battery performance using 'simulated body fluid' as electrolyte}

According to the discussion in section 3.2, it is found that the

35 cathode material made from $0.1 \mathrm{M}$ pyrrole + CNT has the best discharge performance in the protein-free simulated body fluid. Therefore, in this section, only this type of cathode was used to assemble the batteries being tested in electrolytes with different protein concentrations. Fig.7 presents the discharge curves of

40 batteries using different electrolytes with different levels of bovine serum albumin (BSA). It is notable that all the discharge curves turn out to be smoother than those in Fig. 4, indicating that the discharge potentials are stabilized by the protein. Meanwhile, the discharge plateaus are prolonged significantly after adding $8 \mathrm{~g}$ $45 \mathrm{~L}^{-1}$ and $16 \mathrm{~g} \mathrm{~L}^{-1}$ BSA.

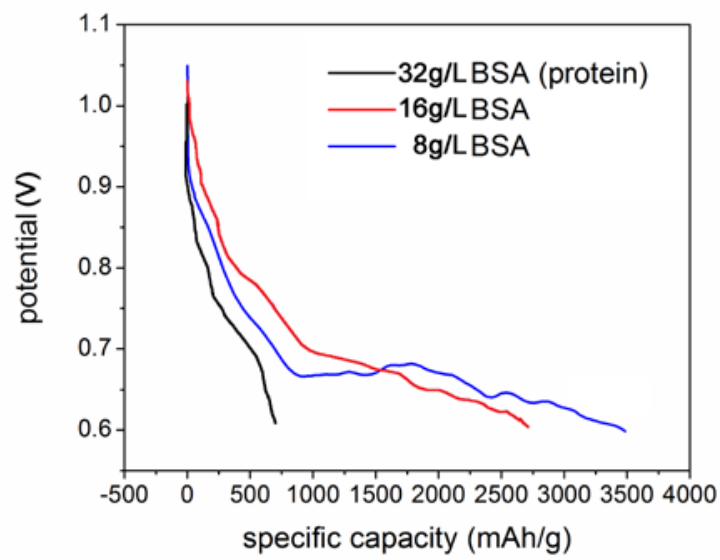

Fig.7 Discharge curves of batteries with simulated body fluid electrolyte containing (a) $8 \mathrm{~g} \mathrm{~L}^{-1} \mathrm{BSA}$, (b) $16 \mathrm{~g} \mathrm{~L}^{-1} \mathrm{BSA}$, (c) $32 \mathrm{~g}$ $50 \mathrm{~L}^{-1}$ BSA.

It is interesting to discuss the effects of the BSA concentration on the battery discharge processes. The anode and cathode reactions of the battery can be described by the electrochemical equations 55 below

$$
\begin{array}{ll}
\text { Cathode } & \mathrm{PPy}^{+}+\mathrm{e}^{-} \leftrightarrow \mathrm{PPy}^{0} \\
& \mathrm{O}_{2}+2 \mathrm{e}^{-}+2 \mathrm{H}_{2} \mathrm{O} \rightarrow 2 \mathrm{OH}^{-} \\
\text {Anode } & \mathrm{Zn} \rightarrow \mathrm{Zn}^{2+}+2 \mathrm{e}^{-} \\
& \mathrm{Zn}^{2+}+2 \mathrm{OH}^{-} \rightarrow \mathrm{Zn}(\mathrm{OH})_{2} \\
& \mathrm{Zn}(\mathrm{OH})_{2} \rightarrow \mathrm{ZnO}+\mathrm{H}_{2} \mathrm{O}^{25}
\end{array}
$$

The cathode reaction is mainly the oxygen reduction process along with the reversible redox process of PPy, while the anode reaction is the oxidation process of zinc described by the 65 equations above. The BSA molecule can affect the electron transfer process and thus slow down the redox reactions on both sides, especially the interface reactions of the zinc electrode.

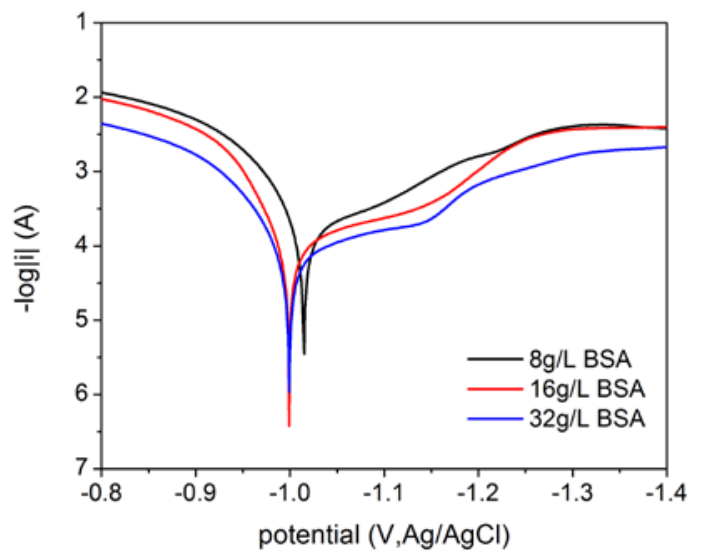

\section{0}

Fig.8 Polarization curves of zinc foil in simulated body fluids containing (a) $8 \mathrm{~g} \mathrm{~L}^{-1} \mathrm{BSA}$, (b) $16 \mathrm{~g} \mathrm{~L}^{-1} \mathrm{BSA}$, (c) $32 \mathrm{~g} \mathrm{~L}^{-1} \mathrm{BSA}$. 
Fig. 8 shows the polarization curves of zinc foil in the three types of electrolyte. In the presence of the organic substances, the cathodic wave shows characteristic inhibition waves. The waves can be explained as due to the absorption of the organic species,

5 and they demonstrate the inhibition efficiency ${ }^{26}$. The length and height of such a wave correspond to the inhibition efficiency, which is mainly decided by the BSA concentration. This can explain why the discharge potential drops so quickly in the battery with electrolyte containing $32 \mathrm{~g} \mathrm{~L}^{-1}$ BSA. In this case, a

10 large amount of big organic molecules can be adsorbed and cover the zinc surfaces, which hinders the interface reaction of the zinc electrode. Diffusion of the oxidation products on the zinc electrode is blocked by the adsorbed organic molecules, making the battery inactive. When the concentration of the organic

15 molecules is low, however, it could slow down the loss of electrons from the zinc electrodes and thus allow the battery to display a longer discharge plateau, as shown in Fig. 7(c).

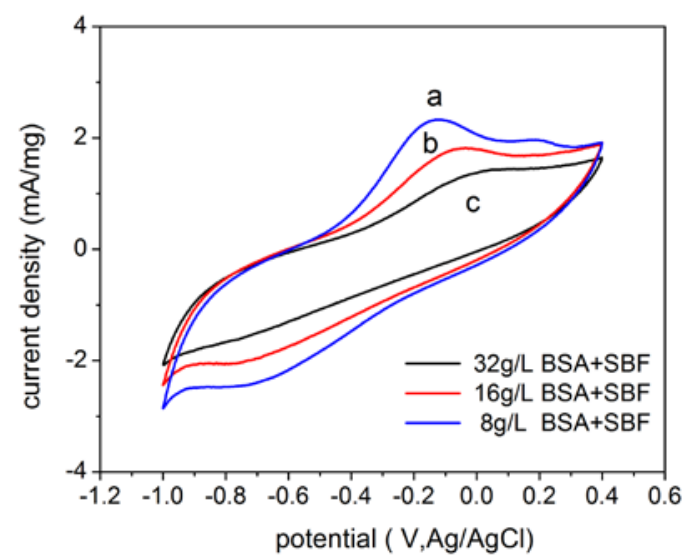

20 Fig.9 Cyclic voltammetry of electrodes made from $0.1 \mathrm{M}$ pyrrole $+0.4 \mathrm{mg} \mathrm{ml}^{-1} \mathrm{CNT}$ in electrolyte containing (a) $8 \mathrm{~g} \mathrm{~L}^{-1} \mathrm{BSA}$, (b) $16 \mathrm{~g} \mathrm{~L}^{-1} \mathrm{BSA}$, (c) $32 \mathrm{~g} \mathrm{~L}^{-1} \mathrm{BSA}$ (scan rate $10 \mathrm{mV} \mathrm{s}^{-1}$ ).

On the other hand, the redox peaks in the CV curves (Fig. 9) of

25 the batteries with different BSA concentrations in the electrolyte have generally become broader than those of the electrodes tested in protein-free SBF. This indicates that the ionic charge transfer processes were retarded when BSA was added to the electrolyte. The bovine serum albumin is a long chain molecule composed of

30 several hundred amino acids. The viscosity of its aqueous solution increases significantly with increasing solute concentration. Therefore, the retardation of ionic charge transfer becomes more obvious when the BSA concentration increases, inducing a drop in the discharge plateau and lower discharge

35 capacity.

\section{Conclusions}

Three types of PPy/CNT composite with varied PPy content were successfully synthesized by chemical polymerization. The 95 morphologies of the composites showed porous structures with

40 PPy particles coated on CNT fibers. A series of batteries was constructed by using PPy/CNT composite deposited on cellulose paper as the cathode and zinc foil as the anode. The composite made from $0.1 \mathrm{M}$ pyrrole $+0.4 \mathrm{mg} \mathrm{ml}^{-1} \mathrm{CNT}$ had the best discharge performance. It also had the best stability and the 45 highest discharge capacity in the simulated body fluid.
Experiments aimed at testing the battery with electrolyte containing proteins were conducted with this type of cathode material. It was found that a small amount of BSA protein can stabilize the discharge potential and prolong the discharge plateau.

50 However, as the protein concentration increased, the ionic charge transfer process can be retarded by the large protein molecules, inducing the decrease of discharge plateau potential and the discharge capacity.

\section{Acknowledgments}

55 The authors are grateful for funding from the Australian Research Council (ARC) under the ARC Centre of Excellence Program.

\section{Notes and references}

${ }^{a}$ Institute for Superconducting and Electronic Materials, University of 60 Wollongong, NSW 2500, Australia,

${ }^{b}$ ARC Center of Excellence for Electromaterials Science, University of Wollongong, NSW 2500, Australia,

Corresponding author email: Hua@uow.edu.au, Fax, +61 242215731

$65+$ Electronic Supplementary Information (ESI) available: [details of any supplementary information available should be included here]. See DOI: $10.1039 / \mathrm{b} 000000 \mathrm{x} /$

70

1. A. Baptista, J. Martins, E. Fortunato, R. Martins, J. Borges and I. Ferreira, Biosensors and Bioelectronics, 2011, 26, 2742-2745.

2. F. F. Ajayi and P. R. Weigele, Bioresource Technology, 2012, 116, 75 86-91.

3. H. Jimbo and N. Miki, Sensors and Actuators B: Chemical, 2008, 134, 219-224.

4. M. Z. Munshi and A. P. Nedungadi, Google Patents, 1995.

5. R. A. Powers, Proceedings of the IEEE, 1995, 83, 687-693.

80 6. S. Passerini, F. Coustier and B. Owens, Journal of power sources, 2000, 90, 144-152.

7. K. B. Lee, Journal of Micromechanics and Microengineering, 2006, 16, 2312.

8. V. S. Mallela, V. Ilankumaran and N. S. Rao, Indian pacing and 85 electrophysiology journal, 2004, 4, 201.

9. W. Greatbatch, C. Holmes, E. Takeuchi and S. Ebel, Pacing and clinical electrophysiology, 1996, 19, 1836-1840.

10. K. B. Lee, Journal of Micromechanics and Microengineering, 2005, 15, S210.

90 11. J. Rao and G. Richter, Naturwissenschaften, 1974, 61, 200-206.

12. X. Wei and J. Liu, Frontiers of Energy and Power Engineering in China, 2008, 2, 1-13.

13. V. L. Pushparaj, M. M. Shaijumon, A. Kumar, S. Murugesan, L. Ci, R. Vajtai, R. J. Linhardt, O. Nalamasu and P. M. Ajayan, Proceedings of the National Academy of Sciences, 2007, 104, 13574-13577.

14. D. A. Nayagam, R. A. Williams, J. Chen, K. A. Magee, J. Irwin, J. Tan, P. Innis, R. T. Leung, S. Finch and C. E. Williams, Small, 2011, 7, 1035-1042.

00 15. E. J. Kelly, C. J. Quaife, G. J. Froelick and R. D. Palmiter, The Journal of nutrition, 1996, 126, 1782-1790. 
16. G. J. Fosmire, The American journal of clinical nutrition, 1990, 51, 225-227.

17. E. I. Dorozhkina and S. V. Dorozhkin, Colloids and Surfaces A: Physicochemical and Engineering Aspects, 2002, 210, 41-48.

5 18. Y.-C. Liu, B.-J. Hwang, W.-J. Jian and R. Santhanam, Thin Solid Films, 2000, 374, 85-91.

19. T. M. Wu and S. H. Lin, Journal of Polymer Science Part B: Polymer Physics, 2006, 44, 1413-1418.

10

20. E. T. Thostenson, Z. Ren and T.-W. Chou, Composites science and technology, 2001, 61, 1899-1912.

21. B. Winther-Jensen, M. Gaadingwe, D. Macfarlane and M. Forsyth, Electrochimica Acta, 2008, 53, 5881-5884.

22. Y. Kong, C. Wang, Y. Yang, C. O. Too and G. G. Wallace, Synthetic Metals, 2012, 162, 584-589.

15 23. A. Lasia, in Modern aspects of electrochemistry, Springer, 2002, pp. 143-248.

24. A. Tenno, R. Tenno and T. Suntio, in Telecommunications Energy Conference, 2002. INTELEC. 24th Annual International, IEEE, 2002, pp. 176-183.

20 25. D. Linden and T. B. Reddy, bankbook of batteries, New York, 2002.

26. J. Dobryszycki and S. Biallozor, Corrosion Science, 2001, 43, 13091319. 